\title{
Microbiological Study of Chronic Suppurative Otitis Media
}

*Shumi RN $N^{1}$, Siddiqe $A^{2}$, Akter $A^{3}$

\begin{abstract}
Chronic suppurative otitis media (CSOM) is a prevailing and notorious infection in developing countries causing serious local damage and threatening complications. The purpose of the present study was determine the microbiological profile of isolates from discharge in CSOM. This study was conducted at out-patient department of ENT at Rajshahi Medical College Hospital, Rajshahi from January 2014 to December 2014. Samples were taken from 185 patients (both male and female) in all age groups suffering from chronic suppurative otitis media. Their Gram staining, culture, and biochemical tests were carried out to identify the organisms. It showed the predominance by staphylococcus aereus (29.13\%), followed by Pseudomonas Aeruginosa (22.83\%), Streptococcus Pyogen (14.96\%), E.Coli (9.44\%), Proteus Mirabilis (6.29\%), Klebsiella Pneumonia(4.72\%).
\end{abstract}

Key words: Chronic suppurative otitis media. microbiological study, CSOM for gram Staining.

\section{INTRODUCTION}

Otitis media is the infection of the middle ear including eustachian tube when get blocked with fluid ${ }^{1}$ mucus, pus and bacteria can also pool behind the ear drum, causing pressure and pain. In a severe ear infection; pressure may build up and cause the ear drum to rupture. Pus and blood may drain out; in most cases ear drum heals on its own. Otitis media is of three types such as acute purulent otitis media, otitis media with effusion and chronic supportive otitis media. ${ }^{1-2}$

Ear infections usually start with cold. They are most common in infant and young children with a peak incidence between 4-7 years old. Otitis media is common in infant and young children due to horizontal eustachian tubes are narrower than adult. Otitis media is a common community

1. *Dr. Rifat nousin shumi, Assistant Porfessor of Microbiology, International Medical College, Tongy. Cell Ph: +88 01942000357

2. Professor. Abdullah Siddiqe, Professor and Head of Microbiology. Barind Medical College, Rajshahi.

3. Dr. Arefa akter, Assistant Porfessor of Microbiology, Rangpur Medical College, Rangpur

*For Correspondence health disorders of children in all developing countries like Bangladesh which causes significant impact in speech, ${ }^{3}$ cognative, educational and psychological development. Patient of otitis media present with pain or discomfort, coughing, nasal congestion, fever, irritability, sleeplessness, sore throat and ear discharge. Fever, vertigo and otalgia should prompt urgent referral to intratemporal or intracranial complications. Hearing loss is common in the affected ear. About $60 \%$ of cases of otitis media is caused by bacteria, occasionally by fungi and viruses. ${ }^{1}$ The bacteria most commonly causing otitis media are Psedomonas aeruginosa causing 20\%-40\%, Staphylococcus Aureus is $20 \%-30 \%$, Streptococcus spp. is $10 \%-20 \%$ and other bacteria include Klebsiella spp., Proteus spp., E coli etc. ${ }^{4}$

Fungal infections of the middle ear are common where there is bacterial infection is present, moist environment helps fungal growth. The most commonly found fungi are Candida species and Aspergillus species. ${ }^{5}$

In a study from India, fungus was found in $15 \%$ of cases, out of which $60 \%$ were Candida species and $40 \%$ were Aspergillus species. In another study from Singapore, fungus accounted for $8.8 \%$ of the total isolates, out of which Aspergillus species was found in $33.3 \%$ followed by Candida species $22.2 \% .^{6}$ Rhinovirus is a common virus that causes sore throat and plays a leading role in the development of ear infections by other bacteria. Other viruses, such as respiratory syncytial virus and influenza virus may also be responsible for child hood ear infections.

\section{MATERIALS AND METHODS}

This descriptive study carried on Department of Microbiology and Department of ENT at Rajshahi Medical College Hospital from January 2014 to December 2014.

A total 185 Samples were collected by sterile swab stick .After the external ear canal was rinsed with sterile saline, exudates were collected with sterile swab sticks and were immediately processed. A smear was prepared from the swab and stained by Gram stain. The swabs were cultured on Blood agar media, Mac Conkey's agar media, Chocolate agar plate and Sabouraud's dextrose agar media. The plates were incubated overnight at $37^{\circ} \mathrm{C}$. The growth of organisms were characterized by colony morphology and Gram's staining from the culture plates. 


\section{RESULTS}

Table-I: Distribution of ages in culture positive cases. $(n=127)$

\begin{tabular}{|l|c|}
\hline Age (Years) & Number of culture positive cases \\
\hline$<10$ & $56(44.09)$ \\
\hline $11-20$ & $36(28.35)$ \\
\hline $21-30$ & $16(12.59)$ \\
\hline $31-40$ & $13(10.24)$ \\
\hline $41-50$ & $3(2.36)$ \\
\hline $51-60$ & $2(1.58)$ \\
\hline$>60$ & $1(0.78)$ \\
\hline Total & $127(100)$ \\
\hline
\end{tabular}

The culture samples of the 127 out of 185 patients were positive, yielding 103 bacteria. Fungi were isolated in 11 patients and 13 were mixed growth of both bacteria and fungus. Staphyliccocci Aureus $29.13 \%$ were the most prevalent microorganism isolated followed by $\mathrm{p}$. aeruginosa $22.83 \%$, St.pyogen $14.96 \%$, E. coli $9.44 \%$, p. mirabilis $6.29 \%$, K. pneumonia $4.72 \%$ and St. pneumonae were $1.57 \%$. Among $11.03 \%$ fungal isolates, as fumigatous were $6.29 \%$ and C. Albicans were $4.72 \%$.

Table-II: Bacterial and fungal isolates in culture positive cases. $(n=127)$

\begin{tabular}{|c|c|c|c|}
\hline $\begin{array}{l}\text { Organism } \\
\text { Bacteria }\end{array}$ & Single growth & Mixed growth & Total \\
\hline Staphylococcus aureus & $34(26.77)$ & $3(2.36)$ & $37(29.13)$ \\
\hline Pseudomonas aeruginosa & $26(20.47)$ & $3(2.36)$ & $29(22.83)$ \\
\hline Streptococcus pyogen & $17(13.38)$ & $2(1.57)$ & $19(14.96)$ \\
\hline E.coli & $10(7.87)$ & $2(1.57)$ & $12(9.44)$ \\
\hline Proteus mirabillis & $8(6.29)$ & $0(0.0)$ & $8(6.29)$ \\
\hline Klebsilla pneumoniae & $6(4.72)$ & $0(0.0)$ & $6(4.72)$ \\
\hline $\begin{array}{l}\text { Streptococcus pneumonae } \\
\text { Fungus }\end{array}$ & ae $2(1.57)$ & $0(00)$ & $2(1.57)$ \\
\hline Aspergillas fumigatous & $6(4.72)$ & $2(1.57)$ & $8(6.29)$ \\
\hline Candida albicans & $5(3.93)$ & $1(0.78)$ & $6(4.72)$ \\
\hline Total & $114(89.76)$ & $13(10.24)$ & $127(100)$ \\
\hline
\end{tabular}

Out of 127 culture positive cases $55.11 \%$ were male and $44.88 \%$ were female, most of the cases were from age group less 10 years and $66.93 \%$ cases were detected from rural area and $43.07 \%$ were urban areas.

\section{DISCUSSION}

Chronic suppurative otitis media is frequently encountered in tropical and subtropical areas. ${ }^{7}$ Diagnosis of this diseases in often based solely on the clinical symptoms. Children less than 5 years and more prone to Otitis media due to shorter and more horizonatal Eustachian tube, lower immunity and better adherence of bacteria to epithelial cells than adults. In this study, aural swab are one of the most frequently request for culture and antimicrobial susceptibility tests.

Chronic supportive otitis media is a major public- health problem and persistent diseases with great risk of complications. CSOM is an important cause of preventable hearing loss particularly in the developing world and it may have long- term effects on early communication, language development, auditory processing, educational process, and physiological and cognitive development. Early microbiological diagnosis ensures prompt and effective treatment to avoid such complications. ${ }^{2}$

In our study, males were more commonly affected than females which are nearly similar with the study of kumar et al ${ }^{9}$ in which males were $61.73 \%, 53.92 \%$ and female were $38.26 \%, 45.23 \%$ respectively.

In our study most prevalent in the age groups of less than 10 years and 11-20 years which is comparable to study of Adoga et al. ${ }^{10}$ High prevalence of CSOM in children may be attributed to the fact that they are more prone to upper respiratory tract infections. In the present study, the most common bacterial isolates were St. aereus ( 29.13\%), P.aeruginosa ( $22.83 \%)$, St. pyogen ( $14.96 \%)$, E. coli (9.44\%), P. mirabilis ( 6.29\%), K. pneumonia ( 4.72\%), As. Fumigatous (6.29\%) and C. albicans ( $4.72 \%)$ which is similar to studies performed by Haider and Roa et al. ${ }^{11}$ Otitis media is not an un common disease, encountered by ENT surgeon. ${ }^{12}$ Diagnosis of this disease is usually done by clinical symptoms. But in many cases only clinical symptoms cannot give the real diagnosis. This results in treatment failure and complications such as irreversible destruction of middle ear, facial palsy, intra and extra cranial complications. For this accurate diagnosis or detection of pathogens are essential.

\section{REFERENCES}

1. Block, S.L. 'Causative pathogens, antibiotic resistance and therapeutic considerations in Otitis media', Paediatr. Infect. Dis. J, 1997;16: 449-456.

2. Berman S. 'Otitis media in developing countries. Paediatrics, 1996; 96:126-131.

3. Weiner R., And P.J., Collison. 'Middle ear pathogens in otitis-prone children', South Dakota J.Med., 2003;56:103-107.

4. Minja, B.M. and A. Machemba. 'Prevalence of Otitis media, hearing impairment and cerumen impaction among school children in rural and urban Dar es Salam, Tanzania', Int. J. Pediatr. Otorhinolaryngol., 1996;37: 29-34.

5. Osazuwa F., Osazuwa E., Osime C., Igharo E.A., Imade 
P.E., et al. 'Etiologic agents of otitis media in Benin city, Nigeria', N Am J Med Sci, 2011; 3: 95-8.

6. Collins C.H. and P.H. Lyne. 'Microbiological Methods',5th Edn., Butterworth and Co. Ltd., Ibadan, Nigeria, 2000.

7. Yehia, M.M. Habib and N.M Shehab 'Ear infections', J. Laryngol. Otol.1990;104;387-389

8. Li W.C., N.C. Chiu, C.H. Hsu, K.S. Lee, H.K. Hwange and F.Y. Huang. 'Pathogens in the middle ear effusion of children with persistent otitis media: Implications of drug resistance and complications', J. Microbiol. Immunol. Infect., 2001;34: 190-194.

9. Kumar R., Srivastava P., Sharma M., Rishi S., Nirwan P.S., et al. 'Isolation and antimicrobial sensitivity profile of bacterial agents in chronic suppurative otitms is media patients at $n$ hospital, jaipur'IJPBS, 2013; 3(4):265-269.

10. Adoga A, Nimkur T, Silas O. 'Chronic suppurative otitis media: Socio-economic implications in a tertiary hospital in Northern Nigeria', Pan Afr Med J, 2010;4:3.

11. Haider A. 'Chronic suppurative Otitis media (CSOM): Bacteriological study', The Orion Medial Journal, 2002;13: 13-14.

12. Rao B.N., Reddy M.S., Rippon J.W, 'Medical mycology', 3rd ed. Philadelphia: W.B. Saunders, 1991;644-777. 